Research Article

\title{
Experimental Study on Cracking Behaviour and Strength Properties of an Expansive Soil under Cyclic Wetting and Drying
}

\author{
Tao Li $\mathbb{D}$, Yanqing He, Guokun Liu, Binru Li, and Rui Hou \\ School of Mechanics and Civil Engineering, China University of Mining and Technology, Beijing 100083, China \\ Correspondence should be addressed to Tao Li; lit@cumtb.edu.cn
}

Received 18 June 2021; Revised 22 October 2021; Accepted 1 December 2021; Published 26 December 2021

Academic Editor: Erkan Oterkus

Copyright $\odot 2021$ Tao Li et al. This is an open access article distributed under the Creative Commons Attribution License, which permits unrestricted use, distribution, and reproduction in any medium, provided the original work is properly cited.

\begin{abstract}
Expansive soil is characterized by its unique structural morphology and drastic volume change. With infrastructure increasingly constructed in expansive soil areas, engineering problems caused by the properties of expansive soils have attracted more attention. Cyclic wetting-drying and shear testing were accordingly conducted on an expansive soil from Chengdu area in China. Crack development and shear strength change were analyzed using the Mohr-Coulomb equation for shear strength by fitting the experimental data. The results show the following: (1) With the increase in wetting-drying cycles, the crack ratio increases, the shear strength decreases, and the shear strength parameters gradually decrease at the same rate of change. The applied vertical load reduces the weakening effect of the wetting-drying cycles on the soil structure and strength by restraining the expansion and contraction deformation. (2) By analyzing the number of wetting-drying cycles and the crack images, the crack development (length, direction, etc.) of the expansive soil can be predicted and described. (3) There is a specific linear correlation between the crack ratio and strength that approached a limit value with ongoing wetting-drying cycles. The strength of the expansive soil can therefore be obtained based on crack development, improving the ability of designers to account for the behaviour of expansive soils.
\end{abstract}

\section{Introduction}

Expansive soils have unstable engineering properties, which result in easy expansion when absorbing water and easy contraction when losing water. This volume sensitivity is typically manifested under circumstances of natural rainfall and evaporation. The volume of expansive soil gradually increases when subjected to these cycles over a long period of time. This deformation can cause damage to constructed facilities such as cutting landslides, roadbed rise, embankment collapse and sinkage, uneven building settlement, and cracking, thus resulting in immeasurable economic loss $[1,2]$. Therefore, research on the effects of alternating wetting-drying cycles on the expansive soil is especially necessary for improving engineering design.

The main reason for cracking inside expansive soils is the application of natural wetting-drying cycles, and the existence and development of such cracks inside expansive soils have an important influence on soil strength and side slope stability [3]. Some research has shown that the strength properties of expansive soil are influenced by the clay mineral type and content, plasticity index, free swell index, matric suction, water content, cracks, degree of compaction, dry density, and load [4-9]. Various changes in the properties of an expansive soil can affect its expansion and contraction, causing the soil to develop cracks. As water gradually seeps into and seep out from these cracks, a loss of soil bearing capacity occurs, leading to different engineering failures.

The expansion and contraction deformation of expansive soil consists of both microscopic and macroscopic deformations. Microscopic deformation is reversible under certain circumstances, while the degree of reversibility of macroscopic deformation is related to the amount of deformation of the expansive soil when subjected to wettingdrying cycles [10]. Gili and Alonso [11] constructed a basic microscopic model of unsaturated expansive soil, leading to further investigations of expansive soil with an emphasis on 
the influence of wetting-drying cycles on the soil structure and strength, providing an important way to comprehend the behaviour of expansive soil in detail.

Nowamooz et al. [12] applied repeated wetting-drying cycles to an expansive soil subjected to different vertical stresses to determine the equilibrium for volumetric strains and elastic behaviour at the end of the suction cycles. On this basis, they derived an elastoplastic model parameter for the evaluated expansive unsaturated soil. Nowamooz et al. [13] investigated the mechanical behaviour of an expansive soil without applying vertical stress under different degrees of suction based on the principle of effective stress. Goh et al. [14] measured the soil-water characteristic curve of a sandkaolin mixture and found that the matric suction and shear strength of three sand-kaolin mixtures decreased gradually with increasing wetting-drying cycles. These experimental results were consistent with the Mohr-Coulomb criterion. Chen et al. [15] described the variation in the strength and rate of evaporation over water content under wetting-drying cycles. Han and Vanapalli [16] studied the relationship between the soil-water characteristic curve, suction, and the strength of unsaturated soil and presented a method for predicting the soil strength based on its suction. Xiao et al. [17] explored that the effective cohesion intersects tended to be zero after being subjected to eight wet-dry cycles by consolidated drained triaxial compression tests. However, the change in load has often been considered as a control factor affecting the strength of an expansive soil. Therefore, research on strength changes under different vertical pressures and wetting-drying cycles based on the Mohr-Coulomb criterion has a significant reference value.

Cracking has been identified as a critical manifestation of expansive soil strength. Lee et al. [18] predicted the crack point and direction using a finite element model that was in good agreement with experimental results. Chertkov [19] classified the soil cracking system using the permutation pattern and location relationships. Yazdandoust and Yasrobi [20] concluded that the main seepage pathway in expansive soils consists of cracks by evaluating the results of wetting-drying cycle tests and analyzing electron micrographs of expansive soils. Tang et al. [21] determined that the formation of interaggregate pores constitutes the main feature of structural change inside the soil by observing the crack development process in clay during the application of wetting-drying cycles. The highly negative pore pressures and increasingly disintegrated texture resulting from repeated wetting-drying cycles have been found to degrade the crack pattern development, elastic modulus, water retention, and other soil properties [22]. Therefore, cracking is one of the fundamental reasons for the frequent occurrence of engineering disasters in areas of expansive soil with seasonal alternation.

The degree of development of apparent cracks in an expansive soil due to wetting-drying cycles (especially the relationship between crack characteristics and strength) is of great importance for engineering design practice, as well as engineering disaster prediction and prevention. However, a quantitative description of the strength and crack development of expansive soil under wetting-drying cycles has not been established. Accordingly, in this study, the change in strength and cracking of an expansive soil from Chengdu was evaluated by processing crack images captured during cyclic wettingdrying. And the quantitative relationship among strength, crack number, and wetting-drying cycle times is obtained, as well as the crack evolution law of expansive soil under wettingdrying cycle conditions. It provides an important reference value for engineering stability prediction and safety evaluation from the two explicit factors of soil strength, crack numbers in the construction process of related projects in expansive soil area under wetting-drying condition.

\section{Materials and Methods}

2.1. Expansive Soil. The expansive soil used in this study was taken from a foundation pit construction site near Tazishan Park in Chengdu, China. This soil is accordingly referred to as "Chengdu expansive soil" in this study. The Chengdu expansive soil was yellowish-brown and reddish-brown and was tough in its dry state. The soil had a dense network of cracks on its surface and in its interior. The soil samples were collected from $2.0 \mathrm{~m}$ below the ground and placed in a sealed bag. The soil was later naturally air-dried and broken by the grinder and then passed through a $1 \mathrm{~mm}$ sieve before being evenly distributed in a sealed box for later testing. The collected soil samples were divided into three groups: group one, used to determine the physical properties of the soil samples; group two, used to study the development of cracks under repeated wetting-drying cycles; and group three, used to study the change in strength characteristics due to repeated wetting-drying cycles.

2.2. Physical Properties. First, the basic properties of the expansive soil samples were determined through compaction, X-ray diffraction, and free swelling ratio testing. The results are shown in Table 1 . To prepare the crushed soil samples for X-ray diffraction analysis, the soil sample was first immersed in distilled water and then subjected to centrifugation. The settled clay was collected, and a proper amount of distilled water was added to the collected clay to create a suspension. Finally, $0.7 \mathrm{~mL}$ of this suspension was absorbed into the slide to make naturally fixed photographs for use in the X-ray diffraction analysis. A TTR-III multifunctional X-ray diffractometer was used to conduct the $\mathrm{X}$-ray diffraction with a $\mathrm{Cu}$ radiation source, $50 \mathrm{kV}$ radiation tube voltage, $50 \mathrm{~mA}$ radiation tube current, $5^{\circ}$ initial angle, $40^{\circ}$ termination angle, $0.0001^{\circ}$ measurement accuracy, $10^{\circ} \%$ min scanning rate in step-by-step scanning mode, $0.01^{\circ}$ step angle, and $20^{\circ} \mathrm{C}$ test temperature. According to the results of the X-ray diffraction test in Figure 1, the quartz content of the nonclay minerals in the expansive soil accounted for $62.7 \%$, while clay minerals accounted for only $30.9 \%$ of the soil. Chengdu expansive soil was mainly composed of an illite-montmorillonite mixed layer accounting for $81 \%$ of the total clay minerals, followed by kaolinite at $10 \%$.

2.3. Strength Testing of Chengdu Expansive Soil under Wetting-Drying Cycles. The soil was air-dried, crushed, and sifted through a $1 \mathrm{~mm}$ sieve under natural conditions. By 
TABLE 1: Geotechnical and physical properties of the test soil.

\begin{tabular}{lc}
\hline Property & Value/constituents \\
\hline Natural moisture content in situ & 22.35 \\
Optimum water content & 18.5 \\
Liquid limit & 41.69 \\
Plastic limit & 19.01 \\
Maximum dry density & 1.73 \\
Saturated water content & 32.0 \\
Free swelling ratio & 47.1 \\
Shrinkage limit & 4.5 \\
Major clay minerals & Montmorillonite and kaolinite \\
\hline
\end{tabular}

preliminary experiments, it is found that the soil has similar crack development and strength change trends when the water content is different under wetting-drying cycles. Therefore, distilled water was then added to the $376 \mathrm{~g}$ soil sample (dry density of $1.6 \mathrm{~g} / \mathrm{cm} 3$ ) to provide a representative water content of $18 \%$, which is close to the optimum water content wf, and the soil was soaked for 24 hours to yield a wet soil weight of $443.68 \mathrm{~g}$.

The compaction method was employed in these experiments using a compacted soil cake with a thickness of $30 \mathrm{~mm}$ and a diameter of $10 \mathrm{~mm}$. After compaction, $61.8 \mathrm{~mm}$ diameter and $20 \mathrm{~mm}$ thick soil samples were removed from the soil cake using a cutting ring. Six groups of tests were carried out in this study, and each group consisted of five soil samples subjected to vertical pressures of $25 \mathrm{kPa}, 50 \mathrm{kPa}$, $100 \mathrm{kPa}, 200 \mathrm{kPa}$, and $300 \mathrm{kPa}$. Therefore, a total of 30 samples were evaluated. A total of 0 (before any cycles were applied), 1, 2, 3, 4, and 5 wetting-drying cycles were applied in this study, corresponding to Group 1, Group 2, Group 3, Group 4, Group 5, and Group 6, respectively. The same wetting-drying cycles were first applied to each of the five samples in each group, and then each of the five samples was sheared to test its strength. The schematic diagram of the test procedure is shown in Figure 2(a).

The cyclic water content magnitude was maintained between $4.5 \%$ of the shrinkage limit moisture content and $32 \%$ of the saturated moisture content using the weighing method. Specifically, during the drying process, the sample was weighed by electronic balance every $3 \mathrm{~min}$ to determine its water content. When the water content of the soil sample was close to $20 \%$, the sample was weighed every $1 \mathrm{~min}$ until the water content reached $18 \%$. At that time, the five soil samples of Group 1 were selected to conduct shear testing under the five vertical pressures mentioned above using a strain-controlled direct shear apparatus. During the shear test, a shear rate of $0.8 \mathrm{~mm} / \mathrm{min}$ was applied until the strengths of the soil samples were obtained. After the first wetting-drying cycle, the five soil samples of Group 2 were tested. The same process was repeated until all six groups were processed. The wetting-drying cycle test process for the expansive soil samples is shown in Figure 2(b).

In order to ensure that the sample could expand evenly and avoid external interference during the humidification process, it was humidified for 24 hours using the steam humidification method, shown schematically on the left in Figure 2(b). After moisture absorption, the external shape of the sample was found to be basically unaffected, and the water contents in different parts of the sample were found to be relatively even. For the drying process, in order to avoid the influence of high temperature on the test results, constant $60^{\circ} \mathrm{C}$ low-temperature drying was used, as indicated on the right side in Figure 2(b). The total time from the beginning to the completion of the drying process was $8 \mathrm{~h}$.

2.4. Crack Development Test of Expansive Soil under WettingDrying Cycles. To study the crack development of Chengdu expansive soil under cyclic wetting-drying, the same cyclic procedure described in Section 2.1 was used to prepare $61.8 \mathrm{~mm}$ diameter and $20 \mathrm{~mm}$ thick soil samples by the compaction method. Different from this, at the control point of every cycle (when the water content of the soil samples reached $4.5 \%, 10 \%, 14 \%, 18 \%, 22 \%, 26 \%$, and $32 \%$ during the drying process), a digital camera was used to take photos of the samples. These samples were placed on a flat aluminium plate in order to prevent the process of crack formation in soil from being influenced during the movement of the samples between the humidifying device and the drying device. Clamps were used to minimise sample movement during the movement of the aluminium plates. The obtained digital photos were imported into MATLAB for binary processing, and the processed images of soil samples and cracks were then depicted in AutoCAD to calculate cracking parameters such as the number of cracks and crack ratio (defined as the ratio of the length of cracks to the total initial area of the sample). To validate the obtained experimental law, another group of expansive soils with the same water content and dry density was tested for verification.

\section{Experimental Results and Analysis}

\subsection{Effects of Wetting-Drying Cycles on Expansive Soil Strength}

3.1.1. Effects of Wetting-Drying Cycles on Expansive Soil Shear Strength. The change in the peak strengths (defined by the highest point of each curve) shown in Figure 3 decreased after the first, second, third, fourth, and fifth wetting-drying cycles by $17.02 \%, 8.37 \%, 7.56 \%, 5.97 \%$, and $2.22 \%$, respectively. The peak strength of the expansive soil thus decreased rapidly within the first and second wetting-drying cycles, but the decrease rate attenuated thereafter.

\subsubsection{Effects of Wetting-Drying Cycles on Shear Strength} Parameters. According to the theory of unsaturated soil strength established by Gili and Alonso [11] and the Mohr-Coulomb theory, two important parameters, the internal friction angle and cohesion of the expansive soil, were obtained from the direct shear test to provide a basis for analysis.

The relationship between the shear strength parameters of the expansive soil and the number of applied wettingdrying cycles is shown in Figure 4. It can be seen that, with the increase in the number of wetting-drying cycles, the cohesion and internal friction angle both decrease 


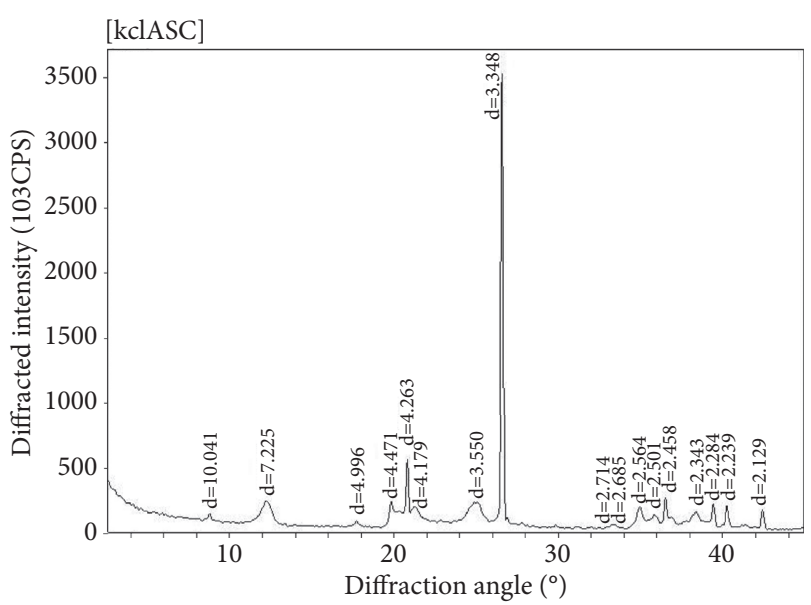

(a)

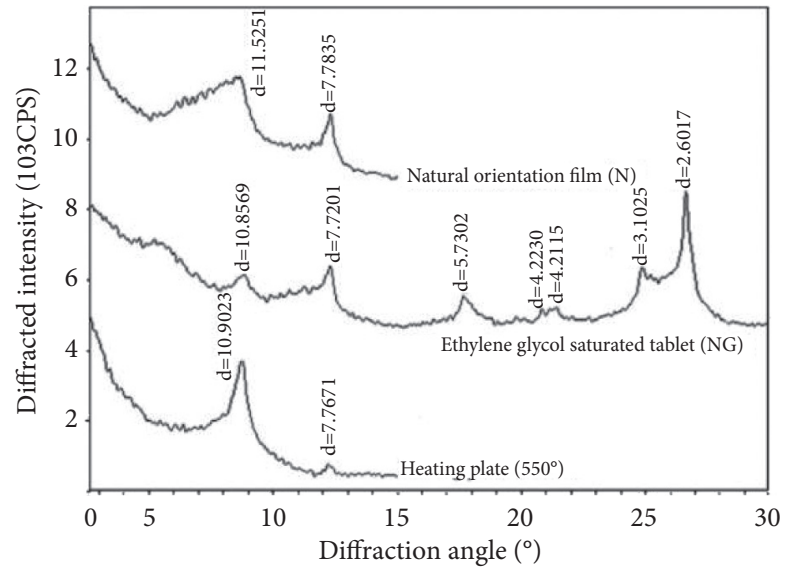

(b)

Figure 1: (a) X-ray diffraction pattern of nonclay minerals; (b) X-ray diffraction pattern of the relative content of clay minerals.

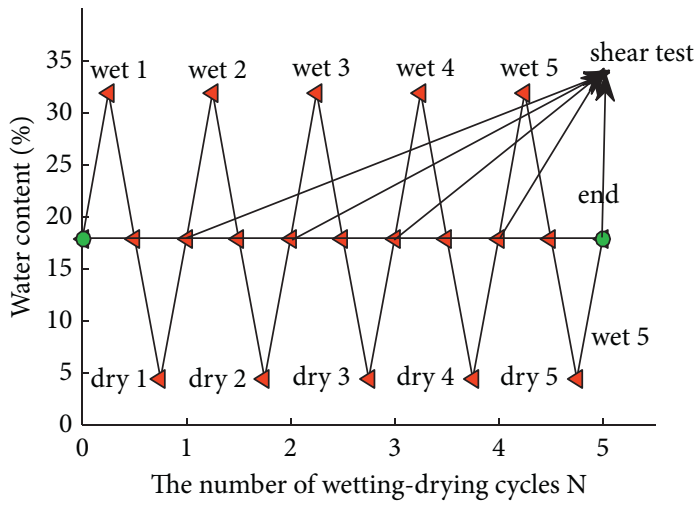

(a)

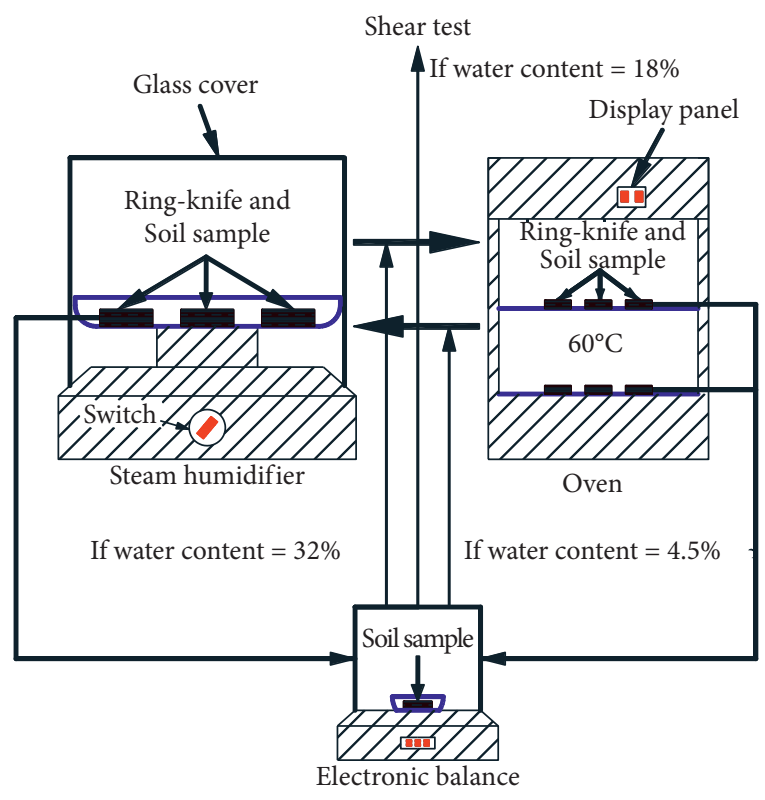

(b)

FIGURE 2: Schematic of the cyclic wetting-drying test procedure. (a) Test procedure. (b) Wetting-drying cycle test process.

exponentially and that this decrease is consistent with the rate of change in the shear strength of the expansive soil.

By fitting and analyzing the test data in Figure 4(a), a welldefined exponential relationship between the cohesion of the expansive soil and the wetting-drying cycles was obtained, providing the best mathematically fit curve as follows:

$$
c_{N}=A_{N} \exp \left(-B_{N} \cdot N+D_{N}\right),
$$

where $c_{N}$ is the cohesion, $N$ is the number of wetting-drying cycles, and $A_{N}, B_{N}$, and $D_{N}$ are parameters related to the initial state. For the soil used in this study, $A_{N}=28.78$, $B_{N}=0.5885$, and $D_{N}=32.99$, with a correlation coefficient of $R^{2}=0.9877$.
The exponential relationship between the internal friction angle and the number of wetting-drying cycles is

$$
\varphi_{N}=E_{N} \exp \left(-F_{N} \cdot N+G_{N}\right),
$$

where $\varphi_{N}$ is the internal friction angle and $E_{N}, F_{N}$, and $G_{N}$ are parameters related to the initial state. In this study, $E_{N}$ $=5.364, F_{N}=0.4012$, and $G_{N}=17.14$, with a correlation coefficient of $R^{2}=0.9893$.

Equations (1) and (2) were substituted into the Mohr-Coulomb shear strength equation to yield a modified shear strength equation for Chengdu expansive soil subjected to different numbers of wetting-drying cycles as follows: 


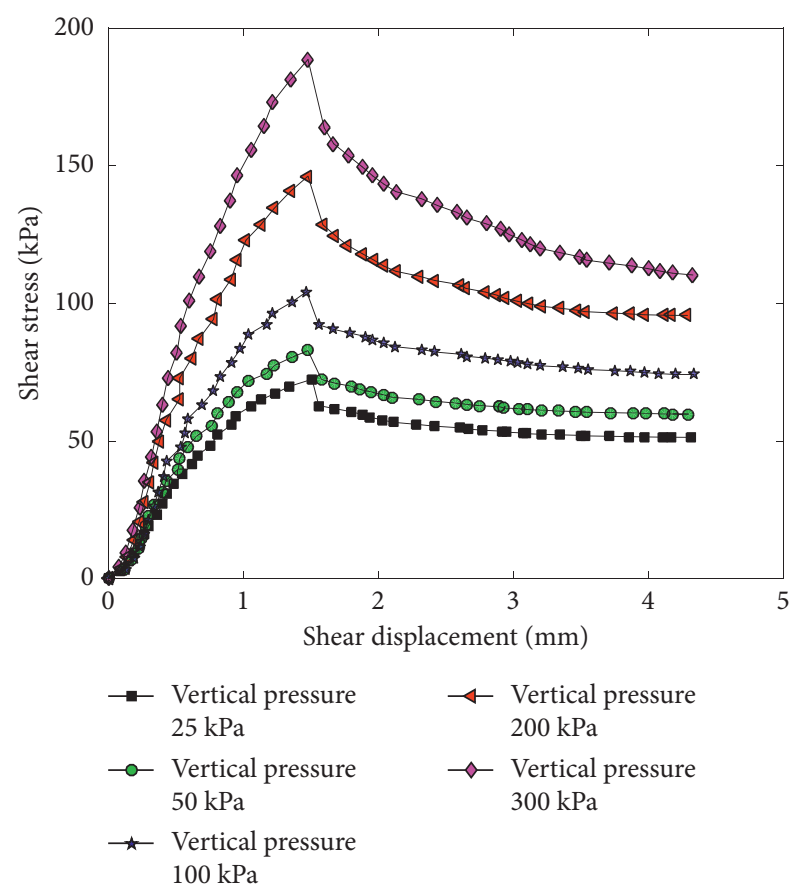

(a)

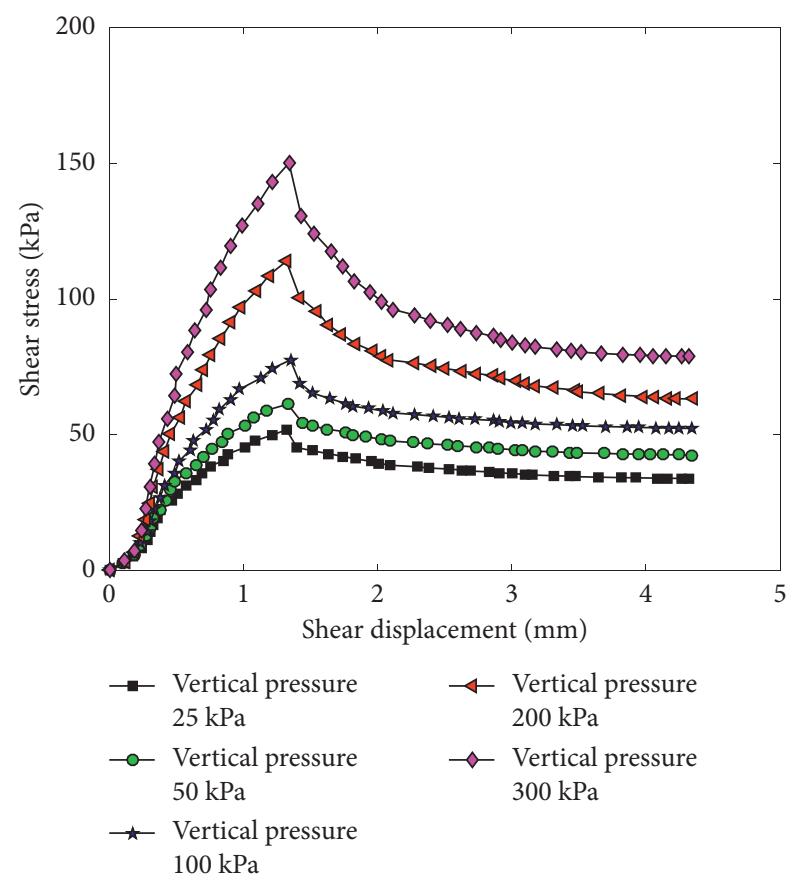

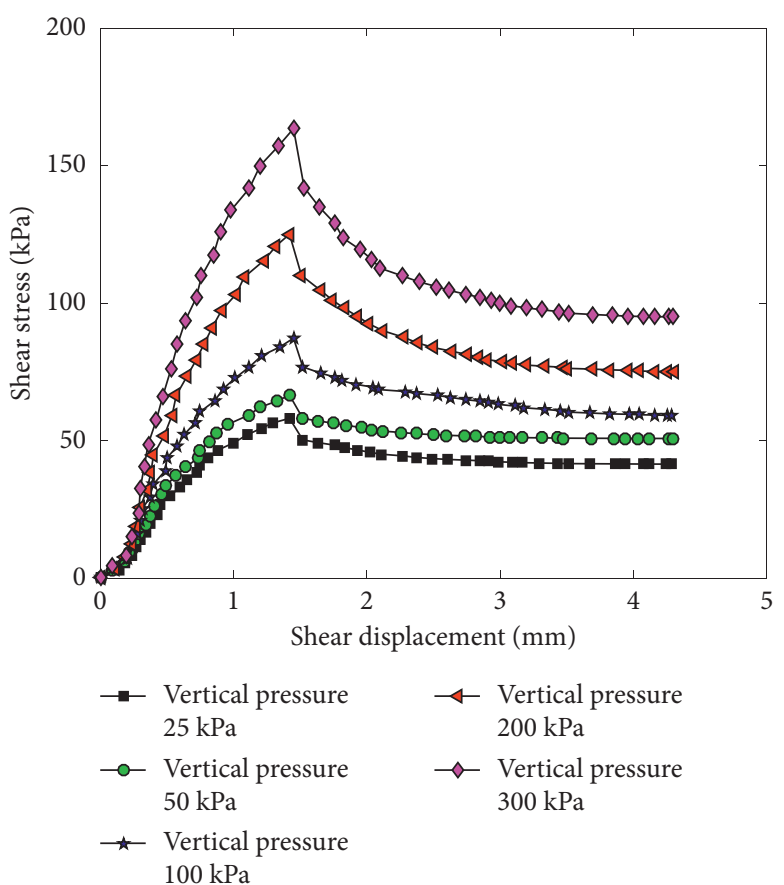

(b)

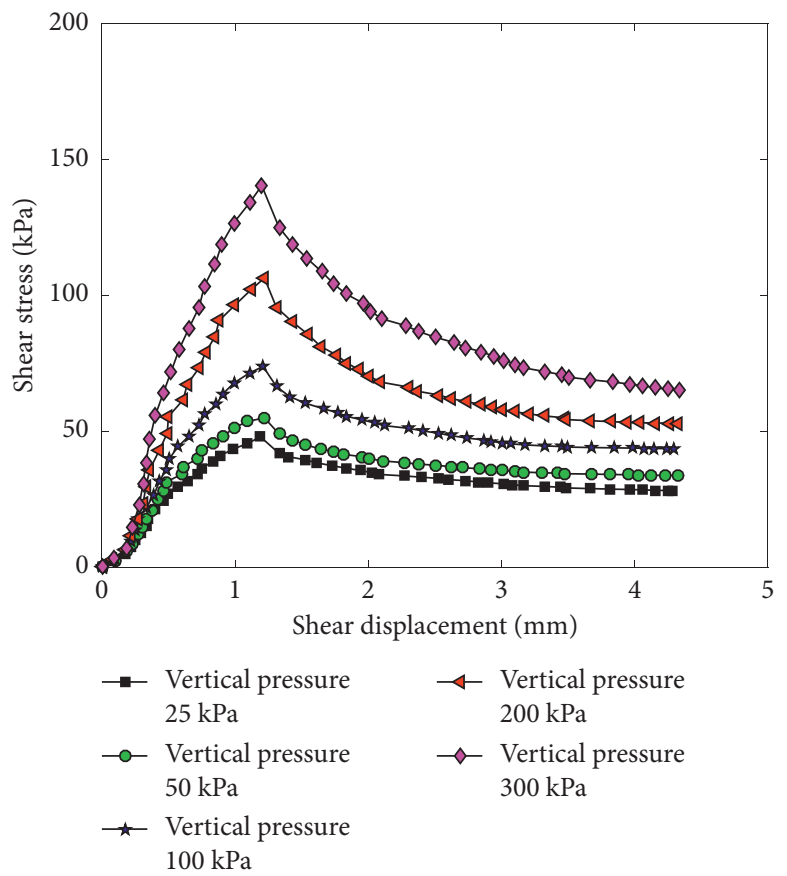

(d)

Figure 3: Continued. 


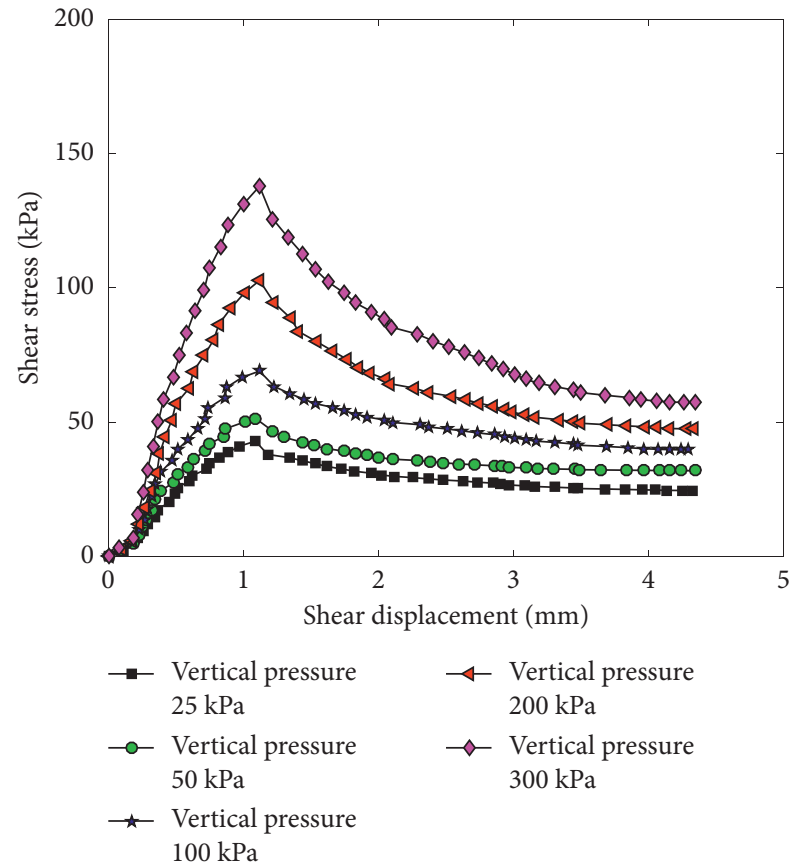

(e)

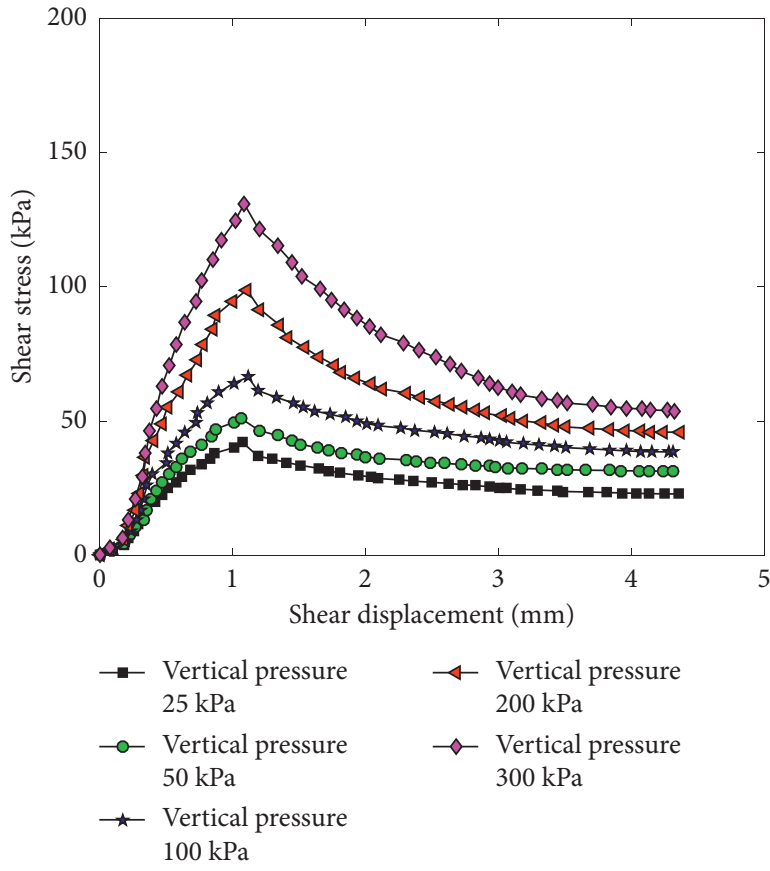

(f)

Figure 3: Shear stress-displacement curves after wetting-drying cycles: (a) zeroth cycle; (b) first cycle; (c) second cycle; (d) third cycle; (e) fourth cycle; (f) fifth cycle.

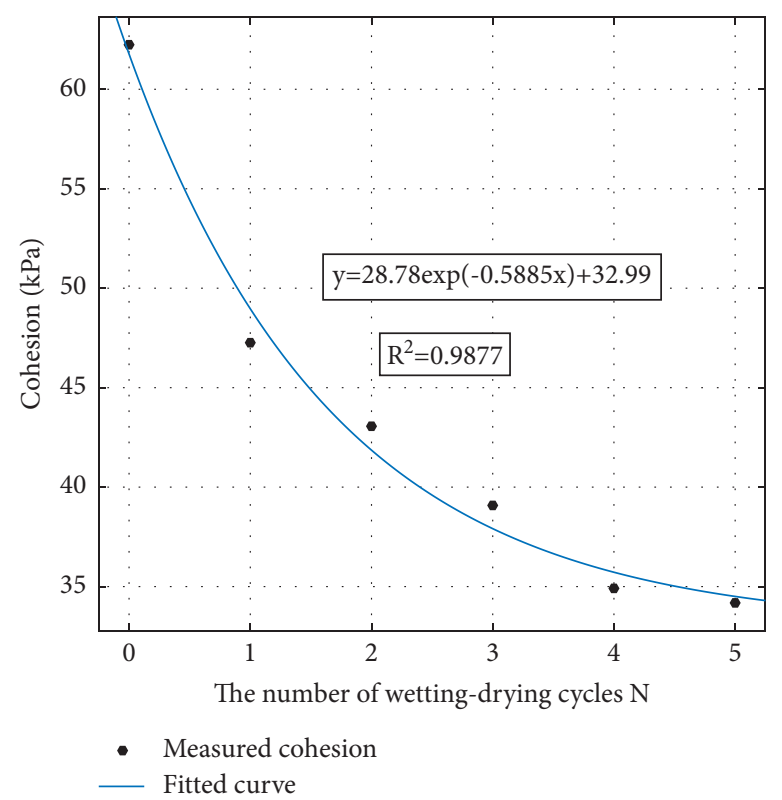

(a)

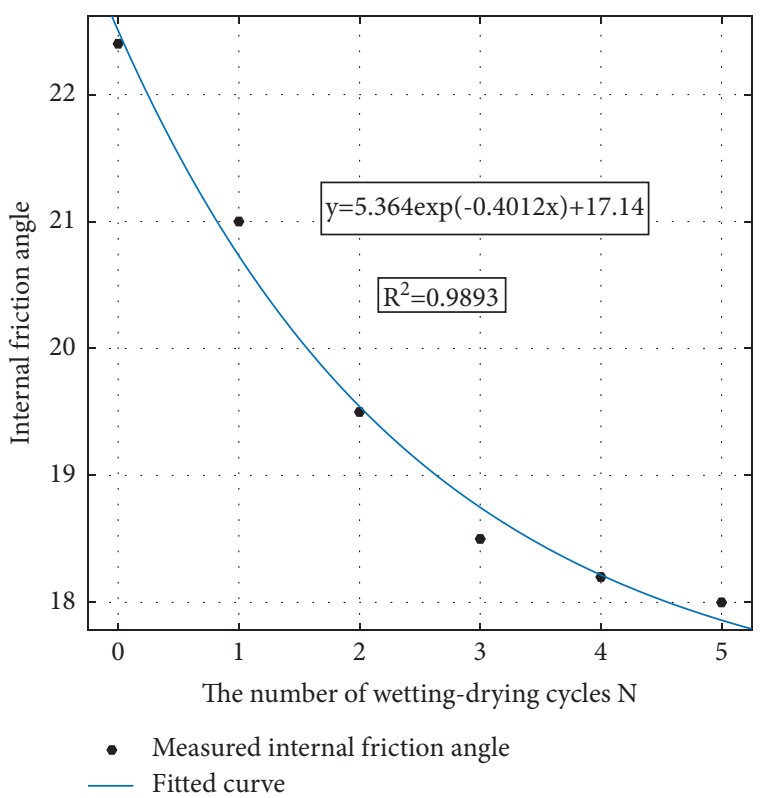

(b)

FIGURE 4: Relationship between shear strength parameters and wetting-drying cycles. (a) Cohesion. (b) Friction angle.

$$
\begin{aligned}
\tau_{f}= & {\left[A_{N} \exp \left(B_{N} \cdot N\right)+D_{N}\right] } \\
& +\sigma \tan \left[E_{N} \exp \left(F_{N} \cdot N\right)+G_{N}\right],
\end{aligned}
$$

where $\tau_{f}$ is the strength of the soil sample after $N$ wettingdrying cycles and $\sigma$ is the vertical pressure on the soil sample.
3.2. Development of Cracks in Samples during Wetting-Drying Cycles. Tang et al. [21] found that the crack ratio was an important index characterizing the degree of crack development in soil when investigating the influence of wettingdrying cycles on crack development in clay. During this shear test, the upper and lower shear box of the direct shear 
apparatus first squeezed the cracks in the shear plane and only then was shear failure induced in the soil, so the crack ratio was used as the quantitative indicator of failure instead of the crack area ratio. A representative group of soil samples was accordingly selected for the quantitative analysis, as described in Section 2.1 and shown in Figure 5. The resulting processed images were obtained by MATLAB and AutoCAD. These processed images were subsequently utilized to calculate the crack ratio and the number of cracks after each wetting-drying cycle. According to the binary processing results of MATLAB, in order to ensure the accuracy of the research results and the integrity of data analysis, we statistically analyze the microcracks produced by expansive soil in dry-wet cycle. The relationship between the crack ratio and water content during the wetting-drying process was fitted and is shown in Figure 6.

In Figure 6, the crack ratio of the expansive soil increases with the increase in the number of wetting-drying cycles when the water content is fixed, and the soil has similar crack development trends when the water content is different under wetting-drying cycles, which is the reason why $18 \%$ water can represent the crack behaviour under wettingdrying cycles. Figure 6 also shows that, during each drying process, the crack ratio increased firstly when the water content decreased from $26 \%$ to $22 \%$ and then decreased as the water content decreased from $22 \%$ to $4.5 \%$.

The relationship between the crack ratio and the number of wetting-drying cycles was fitted using MATLAB, as was the relationship between the number of cracks and the cycle number. The resulting curves are shown in Figure 7.

There was a strong exponential correlation between the crack ratio and the number of wetting-drying cycles with$=0.9882$. The functional relationship between the crack ratio and the number of wetting-drying cycles can be described by

$$
L_{N}=I_{N} \exp \left(-N \cdot K_{N}\right)+H_{N},
$$

where $L_{N}$ is the crack ratio and $I_{N}, K_{N}$, and $H_{N}$ are parameters related to the initial condition of the soil sample before the direct shear test. For the soil used in this test, $I_{N}=-8.73, K_{N}=0.7153$, and $H_{N}=8.846$, with a correlation coefficient of $R^{2}=0.9882$.

In Figure 7, the crack ratio of the expansive soil increases with the increase in the number of wetting-drying cycles, and the curve tends to be flat after the fourth cycle, as can also be seen in Figure 5. These results were consistent with the test results obtained by Zhang et al. [23]. Additionally, equation (4) can be used to predict that the crack length in the $61.8 \mathrm{~mm}$ diameter standard soil sample of Chengdu expansive soil will eventually be stable at about $265.3 \mathrm{~mm}$.

By comparing the processed sample crack development under wetting-drying cycles in Figure 7 with the strength trend in Figure 3, the degree of crack development was found to show a strong correlation with the peak strength, which is basically consistent with previous results of unsaturated soil tests $[14,15]$.

However, the relationship between the crack ratio and the shear strength of the soil obtained in this study can be accurately described by mathematical equations. It can be concluded that there is a positive correlation between the development of the crack ratio and the attenuation of the peak strength of the expansive soil under wetting-drying cycles.

In view of this strong observed correlation, the relationship between the strength and crack ratio of the Chengdu expansive soil was further analyzed. It was found that there was a linear mathematical correlation between the shearing strength and crack ratio, as shown in Figure 8.

The crack images obtained in the verification test are shown in Figure 9. The results show that the crack ratios of the Chengdu expansive soil after the first, second, third, fourth, and fifth wetting-drying cycles are $5.08 \%(1 / \mathrm{mm})$, $6.79 \%(1 / \mathrm{mm}), 7.36 \%(1 / \mathrm{mm}), 8.38 \%(1 / \mathrm{mm})$, and $8.84 \%(1 /$ $\mathrm{mm}$ ), respectively, which are very close to those of the original experiments, and the maximum difference from the original experiments is less than 2.5\%. The relationship between the crack ratio and the number of wetting-drying cycles is thus basically the same, indicating that the experimental data are reliable.

\section{Discussion}

4.1. Mechanism of Crack Initiation and Strength Change during Wetting-Drying Cycles. During the drying process, there were gradual increases in the matric suction of the soil $[23,24]$ as well as the horizontal net stress in the samples. This caused the soil to be pulled in the direction parallel to its surface. When this stress reached the shear strength of the soil, cracks began to appear in the soil samples. According to the description of the reliability of the assumption of linear elasticity for unsaturated soil strength by Graham [25], the prepared soil cakes can be assumed to be a homogeneous isotropic elastomer. Where cracks begin to occur and where cracks are stable, the stress state can be written as

$$
\left(\sigma_{h}-u_{a}\right)+\sigma_{\tau}=0,
$$

where $\sigma_{h}$ is the total stress in the horizontal direction, $u_{a}$ is the pore air pressure, and $\sigma_{\tau}$ is the tensile strength of the soil.

As the drying process continued, the development of cracks gradually stabilised (after a period of vigorous development) at an equilibrium point reached by adjusting the width, direction, branching, and so on of the cracks to release the strain energy (similar to the mechanism of the entropy increase principle in chemistry). This equilibrium point, described by equation (5), is generally located inside the soil at the end of a crack.

When evaluating the change law of the matric suction of a sand-kaolin mixture in relation to the number of wettingdrying cycles, Goh et al. [14] found that the stiffness of the unsaturated soil increased and the suction gradually decreased with increasing cycles. These changes led to the observed decrease in the strength of expansive soil in this experiment. During the drying process, the moisture in the soil evaporated, causing the soil to lose water and shrink and the particles in the soil to move closer to each other. Tensile stress was thus generated between the soil particles so that 


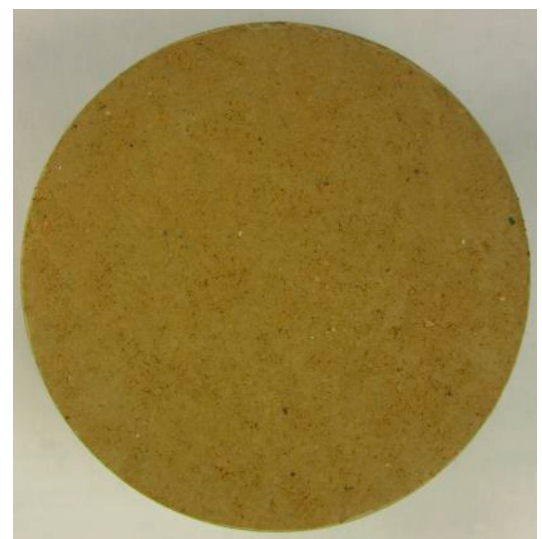

(a)

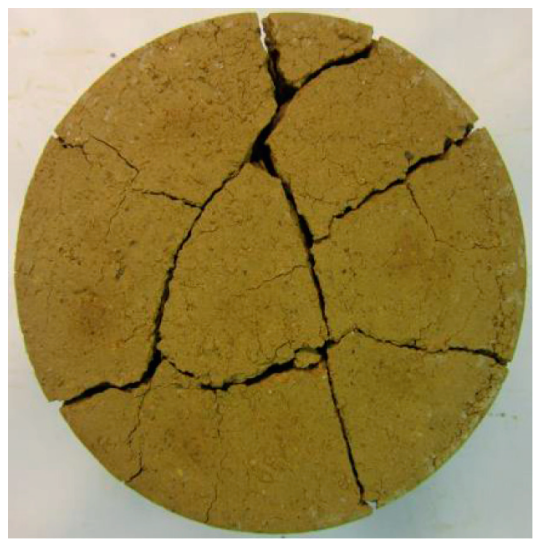

(d)

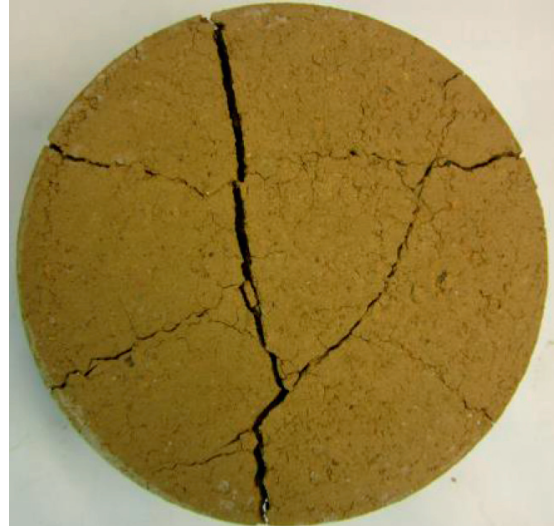

(b)

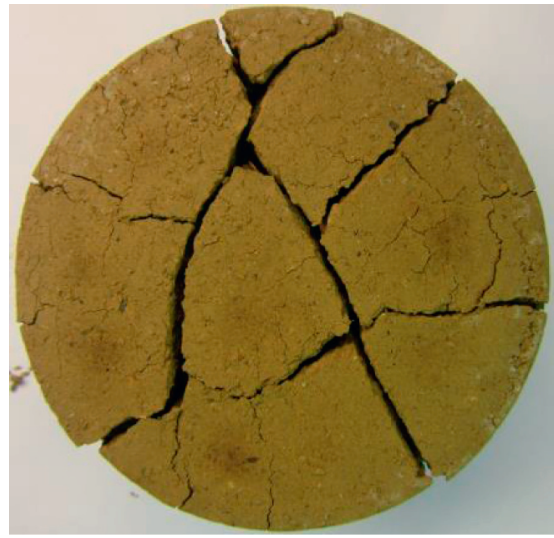

(e)

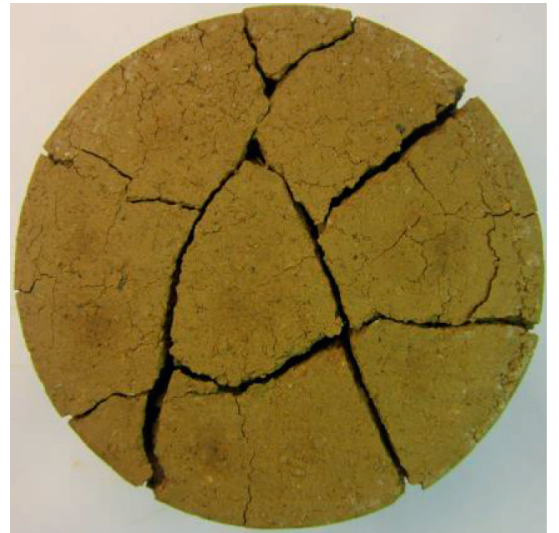

(c)

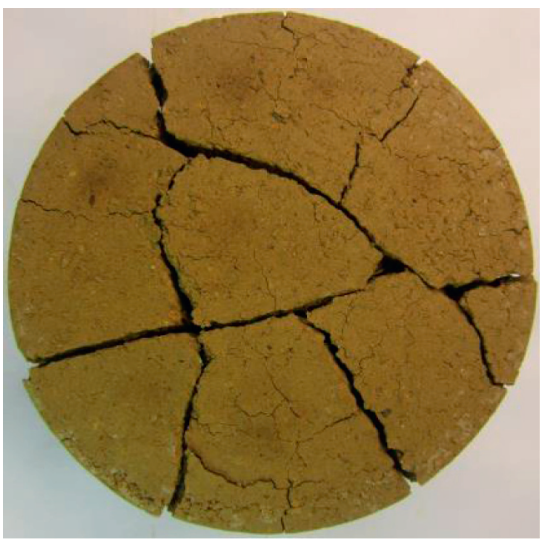

(f)

Figure 5: Images of crack development process. (a) Zeroth cycle. (b) First cycle. (c) Second cycle. (d) Third cycle. (e) Fourth cycle. (f) Fifth cycle.

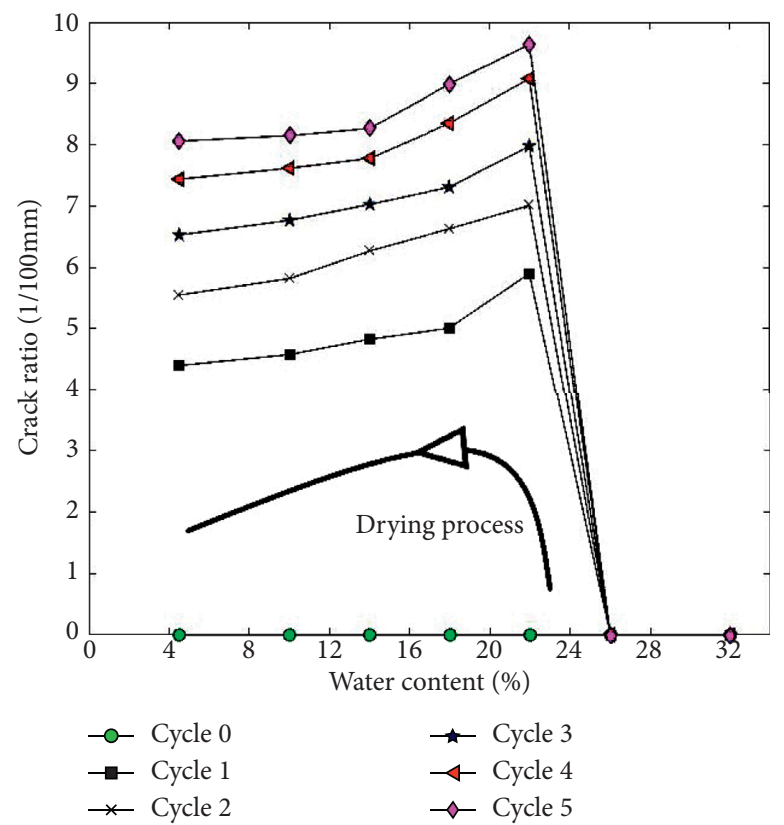

FIGURE 6: Relationship between crack ratio and water content. 


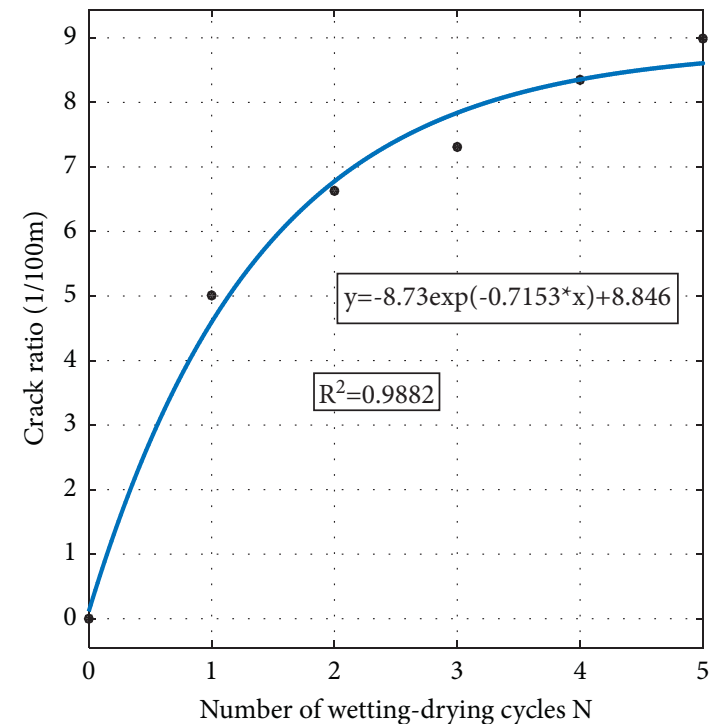

- Calculated crack ratio

- Fitted curve

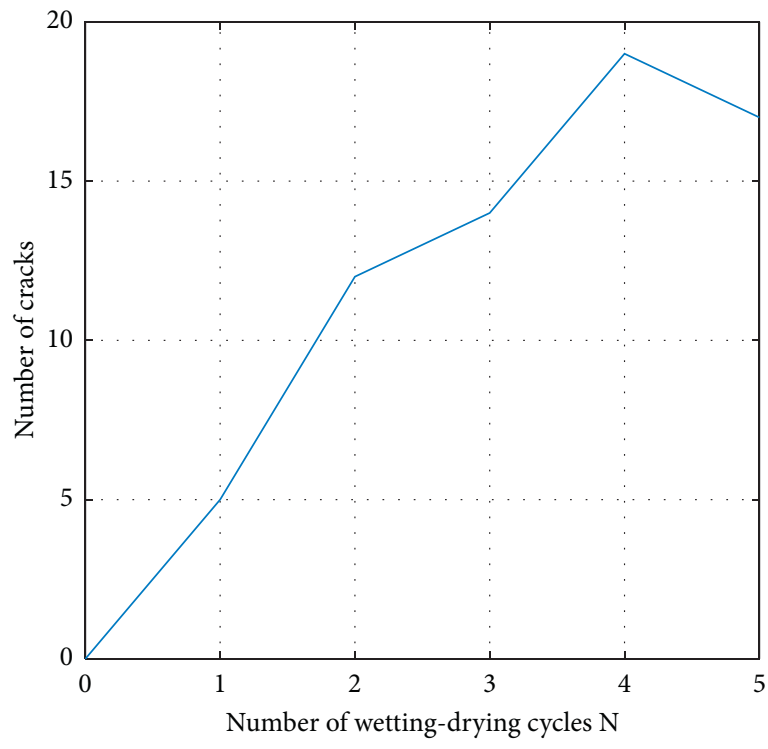

(b)

FiguRe 7: Relationship between crack ratio, number of cracks, and the number of wetting-drying cycles. (a) Crack ratio. (b) Crack number.

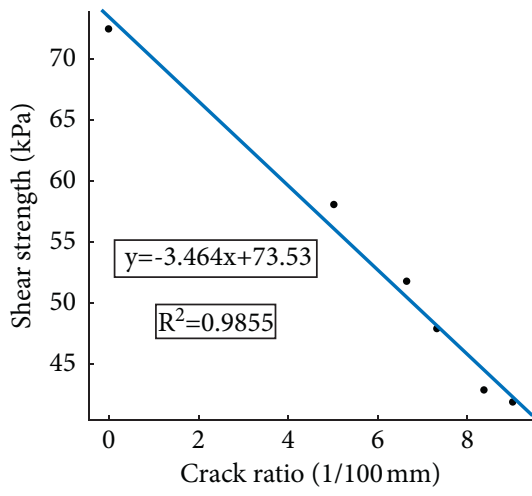

- Measured shear strength - Fitted curve

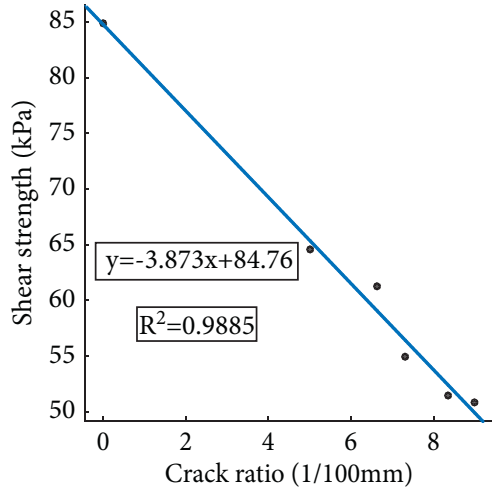

- Measured shear strength — Fitted curve

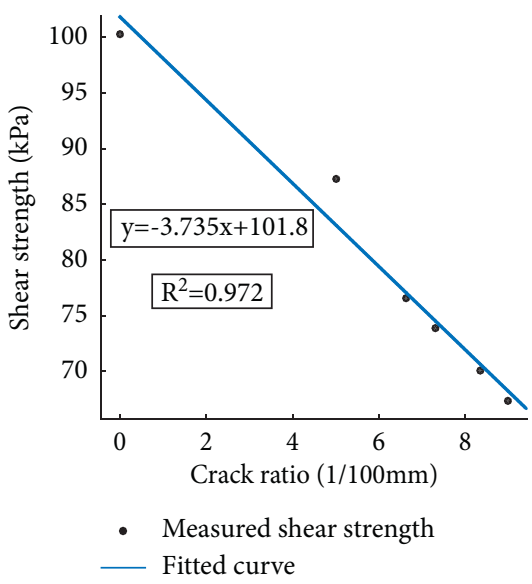

(c)

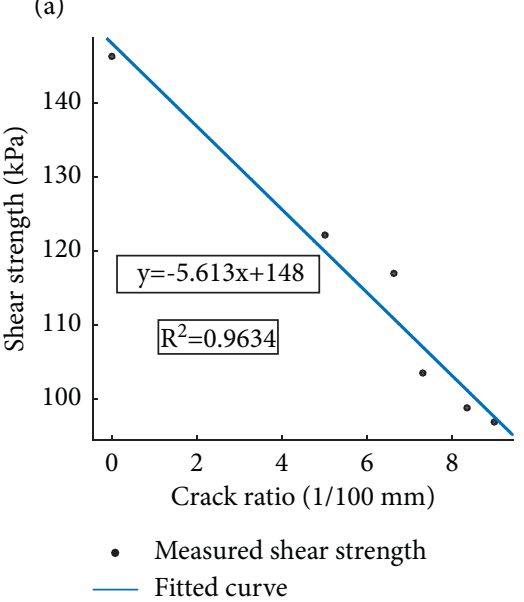

(d) (b)

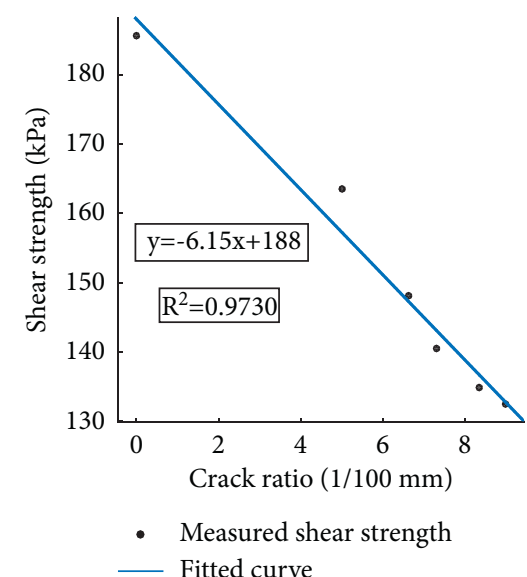

(e)

FiguRE 8: Relationship between crack ratio and shear strength of Chengdu expansive soil under different vertical pressures: (a) $25 \mathrm{kPa}$; (b) $50 \mathrm{kPa}$; (c) $100 \mathrm{kPa}$; (d) $200 \mathrm{kPa}$; (e) $300 \mathrm{kPa}$. 


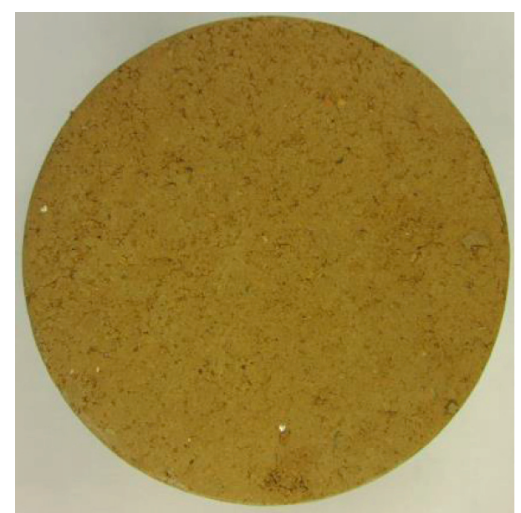

(a)

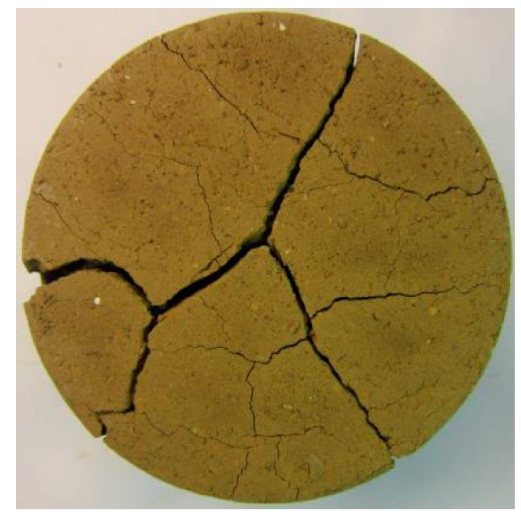

(d)

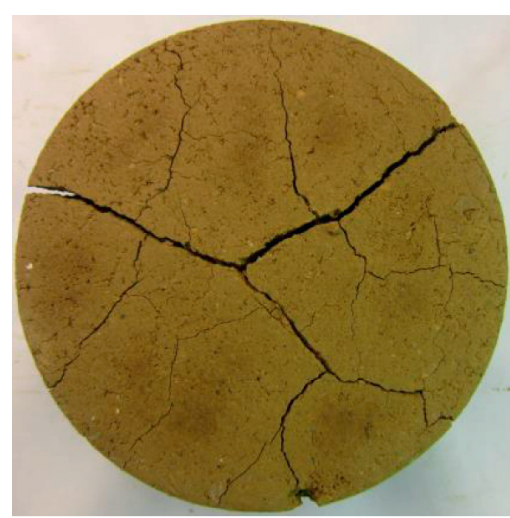

(b)

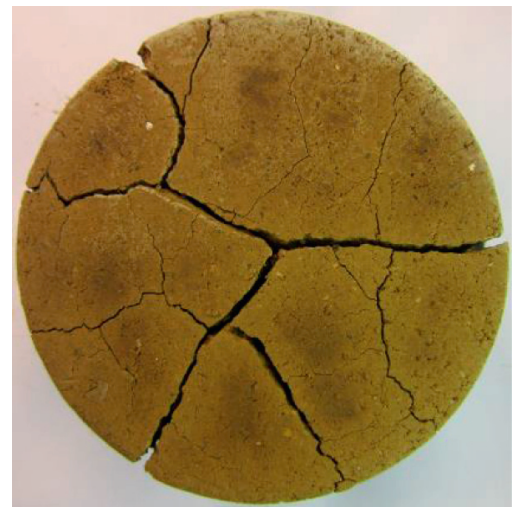

(e)

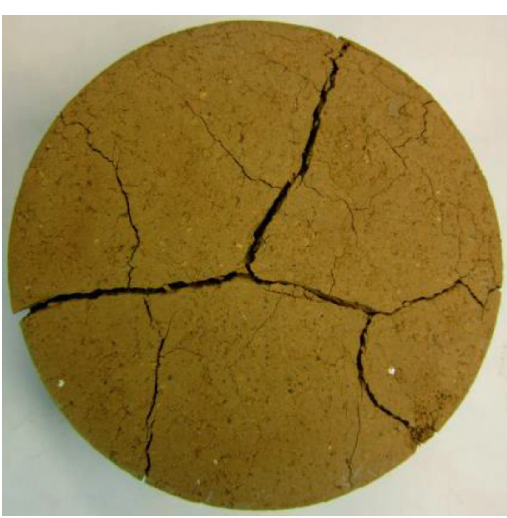

(c)

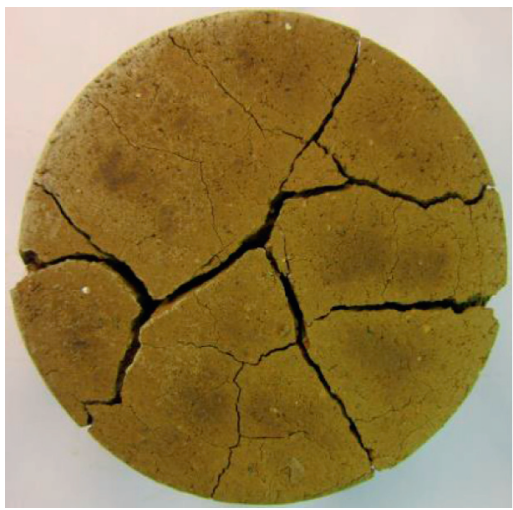

(f)

Figure 9: Images of crack development process in the verification test. (a) Zeroth cycle. (b) First cycle. (c) Second cycle. (d) Third cycle. (e) Fourth cycle. (f) Fifth cycle.

the weak parts in the soil first reached their tensile strengths and released their strain energy, resulting in cracks [26, 27]. Combined with the small initial cracks observed in the original experiment in Figure 5 and in the verification test in Figure 9, it can be inferred that, as the water in the soil evaporated, the main drainage path through the soil continued to be disturbed due to the movement of water vapour. These partially opened voids are difficult to restore to their original state, resulting in irreversible damage to the soil characteristics and decreasing its strength compared to that before the application of wetting-drying cycles.

4.2. Development Mechanism of Cracks in Expansive Soil during Wetting-Drying Cycles. With the increase in the number of wetting-drying cycles, the cracks in the expansive soil continued to develop. During the development process, the crack ratio and the direction of the crack extension both exhibited regular changes.

A crack development processed picture from the first to the second wetting-drying cycle is shown in Figure 10(a). The crack on the left is more complete, while the crack on the right shows a tendency to gradually extend to meet the left crack. Point A is the endpoint from which the right crack extends. In the present study, the crack on the right side of Figure 10(a) is referred to as an active crack, while that on the left is referred to as a passive crack.
In Figure 10(b), the direction of active crack extension is compared to the direction at which the two cracks intersected; the angle between the two directions was $11^{\circ}$. The angles between the other active cracks and their actual crack directions were measured to be $5^{\circ}, 8^{\circ}, 14^{\circ}$, and $7^{\circ}$, with an average value of $9^{\circ}$. When an extant active crack comes close to meeting an extant passive crack, the two will continue to develop along an angle of $\theta=5-15^{\circ}$ from the direction of active crack development. This was proven by subsequent verification tests. Based on this observation and combined with the prediction of the crack ratio and crack length discussed in Section 3.2, the general development of a crack after each wetting-drying cycle can be roughly inferred and sketched.

4.3. Relationship between Shear Strength, Crack Ratio, and Number of Wetting-Drying Cycles. Tang et al. [24] provided a preliminary microscopic explanation of the development of soil cracks in their study of the development of cracks in clay with wetting-drying cycles (similar to the present study). They stated that the formation and development of cracks were mainly the result of the formation and gradual evolution of the soil aggregates. Yazdandoust and Yasrobi [20] conducted in situ and electron micrograph tests on modified expansive soils, finding that the trend of swelling pressure of an expansive soil changed significantly after the 


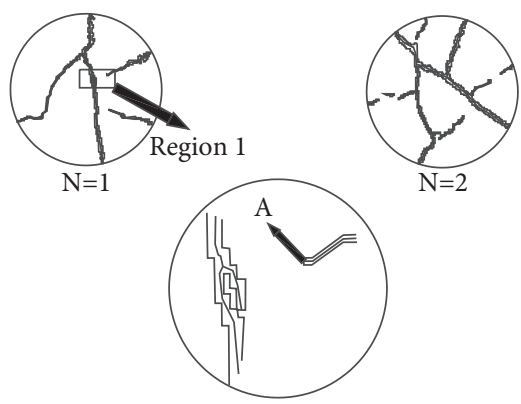

(a)

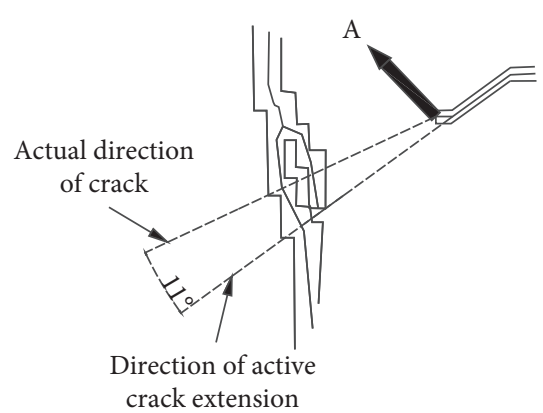

(b)

Figure 10: Schematic diagram of crack development in the first and second cycles. (a) Crack development of the whole specimen. (b) The relationship between active crack and passive crack.

first, second, and third wetting-drying cycles, similar to the change in the shear strength and crack ratio of Chengdu expansive soil evaluated in this study. However, the change in the swelling pressure over the first three cycles obtained by Yazdandoust [20] is approximately 50\%, which is much larger than the changes in strength and crack ratio in this study. It can be assumed that the reason for this difference in the cracking behaviour of expansive soils is that the strength, crack ratio, and swelling pressure of an expansive soil reflect the internal structure of the soil, so similar behaviour of similar soils is inevitable. However, when measuring the swelling pressure, the moisture content of the soil sample is always saturated, and the particles inside the soil are relatively dispersed, so the effect of wetting-drying cycles on the swelling pressure of expansive soil is more intense. Compared with the swelling pressure, the crack ratio has a closer relationship with the shear strength of expansive soil. Therefore, the crack ratio can be a more reasonable index to characterize the strength of expansive soil.

Because the shear test only measures how cracks in the shear plane of the soil will affect its strength, on the basis of the crack ratio-shear strength curves under different vertical stresses (Figure 10), the relationship between the strength and crack ratio of a shear plane is

$$
\tau_{n}=\tau_{0}-k_{c} r
$$

where $\tau_{n}$ is the strength of a certain shear plane in the soil after $n$ wetting-drying cycles, $\tau_{0}$ is the strength of the soil without being subjected to wetting-drying cycles, $k_{c}$ is defined as the phase damage rate of the soil relative to the number of wetting-drying cycles, and $r$ is the crack ratio of the soil along the shear plane in question.

As shown in Figure 8, with the gradual increase in vertical pressure from $25 \mathrm{kPa}$ to $50 \mathrm{kPa}, 100 \mathrm{kPa}, 200 \mathrm{kPa}$, and $300 \mathrm{kPa}$, the slope of the fitted line $k_{c}(\Delta \tau / \Delta r)$ is 3.464 , $3.873,3.735,5.613$, and 6.150 , respectively, showing a gradually increasing trend. This suggests that when the crack ratio of an expansive soil varies within a certain value under wetting-drying cycles, its shear strength decreases with the increase in vertical pressure, indicating that vertical pressure is closely related to the value of $k_{c}$ of expansive soil under wetting-drying cycles.
From Figure 7 and its analysis in Section 3.2, the crack ratio of the Chengdu expansive soil was found to have a certain limit: the value of $r$ in equation (6) had a stable, minimum value corresponding to the shear strength limit of the Chengdu expansive soil with the infinite increase in the number of wetting-drying cycles. The maximum values of the original and validation tests were $8.846 \%$ and $8.627 \%$, respectively, with a difference of $2.48 \%$. This offers powerful proof of the relationship between the number of wetting-drying cycles $N$ and the crack ratio $r$. Accordingly, equation (6) suggests that an expansive soil with specific water content, dry density, and stress state (i.e., specific $k_{c}$ ) can be tested to determine its stability strength because of the limit value of $r$ (which also represents its minimum strength after numerous wettingdrying cycles under natural conditions).

The generation of cracks is a macroscopic representation of the microscopic particle state and structural change of expansive soil. The experimental results of this study show that there is a specific mathematical linear relationship between the change in crack ratio and the change in strength, which provides a basis for predicting the final strength of a treated expansive soil in a construction project and ensures that the design strength of the expansive soil is accurate by evaluating the development status of the cracks.

4.4. Study Limitations. Owing to the limitations of the test conditions applied in this study, it was impossible to continuously observe and evaluate the development of cracks throughout the entire cyclic wetting-drying process. However, the comprehensive predictions of crack development morphology, crack ratio, cracking trend, and the return of shear strength to its natural condition after several wettingdrying cycles resulting from the periodic observations in this study can still be useful. In order to more effectively describe the internal evolution of expansive soils during the cyclic wetting-drying process, more accurate and comprehensive instruments combined with numerical simulation technology could be used to conduct more extensive explorations into the aspects of crack width and depth during crack development. 


\section{Conclusions}

An expansive soil was collected from a Chengdu construction site, and its shear strength was tested. Six groups of soil samples subjected to different wetting-drying cycles were used to determine the correlation between cracking behaviour and strength. In addition, the effects of vertical pressure on Chengdu expansive soil were investigated. The findings of this study are as follows:

(1) As the number of wetting-drying cycles increased, the shear strength (i.e., peak strength) of Chengdu expansive soil initially decreased rapidly and then decreased slowly; the change in shear strength parameters (cohesion and internal friction angle) also initially decreased rapidly before slowing, while the crack ratio increased quickly and then grew slowly.

(2) Vertical pressure had an obvious restraining effect on the swelling and shrinkage deformation and the reduction in strength of the expansive soil during wetting-drying cycles.

(3) A modified Mohr-Coulomb formula for Chengdu expansive soil was obtained by fitting the parameters in the Mohr-Coulomb strength equation to the experimental data.

(4) Through the analysis of the crack ratio and the development of active and passive cracks, the general progression (length, direction, etc.) of crack development after each wetting-drying cycle can be effectively described and predicted.

(5) With the application of wetting-drying cycles, the crack ratio and strength of the expansive soil exhibited certain limits, and there was a specific linear correlation between these parameters. According to these results, the change in strength and crack ratio of the expansive soil with the number of applied wetting-drying cycles can be obtained using the development of cracks. The phase damage rate $\left(k_{c}\right)$ of the soil strength relative to the number of applied wetting-drying cycles was observed to increase with the increase in the vertical pressure and was found to be a key parameter characterizing the rate of soil strength reduction.

\section{Data Availability}

The data used to support the findings of this study are included within the article.

\section{Conflicts of Interest}

The authors declare no conflicts of interest.

\section{Authors' Contributions}

Tao Li and Yanqing He conducted conceptualization; Binru $\mathrm{Li}$ and Rui Hou performed data curation; Tao Li contributed to funding acquisition; Yanqing $\mathrm{He}$ and Binru Li carried out investigation; $\mathrm{TaO} \mathrm{Li}$ and Yanqing $\mathrm{He}$ contributed to methodology; Tao Li, Yanqing He, and Rui Hou provided resources; Tao Li and Guokun Liu contributed to software; Tao Li and Guokun Liu performed validation; Tao Li and Yanqing He wrote the original draft; Yanqing He contributed to review and editing of the paper. All authors have read and agreed to the published version of the paper.

\section{Acknowledgments}

The authors would like to gratefully acknowledge the financial support provided by the National Natural Science Foundation of China. The authors also sincerely acknowledge the China University of Mining and Technology, Beijing, for providing laboratory space and laboratory equipment. This research was funded by the National Natural Science Foundation of China for Young Scholars under Grant no. 51508556.

\section{References}

[1] Z. A. Erguler and R. Ulusay, "Engineering characteristics and environmental impacts of the expansive Ankara Clay, and swelling maps for SW and central parts of the Ankara (Turkey) metropolitan area," Environmental Geology, vol. 44, no. 8, pp. 979-992, 2003.

[2] M. Ito and S. Azam, "Engineering properties of a vertisolic expansive soil deposit," Engineering Geology, vol. 152, no. 1, pp. 10-16, 2013.

[3] R. Baker, "Tensile Strength, tension cracks, and stability of slopes," Soils and Foundations, vol. 21, pp. 1-17, 1981.

[4] F. H. Chen, Foundations on Expansive Soils, Elsevier, Amsterdam, Netherlands, 1988.

[5] A. A. Basma, "Prediction of expansion degree for natural compacted clays," ASTM Geotech. Test. J.vol. 16, pp. 542-549, 1993.

[6] A. S. Rao, B. R. Phanikumar, and R. S. Sharma, "Prediction of swelling characteristics of remoulded and compacted expansive soils using free swell index," The Quarterly Journal of Engineering Geology and Hydrogeology, vol. 37, no. 3, pp. 217-226, 2004.

[7] A. Aldaood, M. Bouasker, and M. Al-Mukhtar, "Impact of wetting-drying cycles on the microstructure and mechanical properties of lime-stabilized gypseous soils," Engineering Geology, vol. 174, pp. 11-21, 2014.

[8] A. R. Estabragh, B. Parsaei, and A. A. Javadi, "Laboratory investigation of the effect of cyclic wetting and drying on the behaviour of an expansive soil," Soils and Foundations, vol. 55, no. 2, pp. 304-314, 2015.

[9] Y.-X. Wang, P.-P. Guo, W.-X. Ren et al., "Laboratory investigation on strength characteristics of expansive soil treated with jute fiber reinforcement," International Journal of Geomechanics, vol. 17, no. 11, Article ID 04017101, 2017.

[10] E. E. Alonso, J. Vaunat, and A. Gens, "Modelling the mechanical behaviour of expansive clays," Engineering Geology, vol. 54, no. 1-2, pp. 173-183, 1999.

[11] J. A. Gili and E. E. Alonso, "Microstructural deformation mechanisms of unsaturated granular soils," International Journal for Numerical and Analytical Methods in Geomechanics, vol. 26, no. 5, pp. 433-468, 2002.

[12] H. Nowamooz, E. Jahangir, F. Masrouri, and J.-P. Tisot, "Effective stress in swelling soils during wetting drying cycles," Engineering Geology, vol. 210, pp. 33-44, 2016. 
[13] H. Nowamooz, M. Mrad, A. Abdallah, and F. Masrouri, "Experimental and numerical studies of the hydromechanical behaviour of a natural unsaturated swelling soil," Canadian Geotechnical Journal, vol. 46, no. 4, pp. 393-410, 2009.

[14] S. G. Goh, H. Rahardjo, and E. C. Leong, "Shear strength of unsaturated soils under multiple drying-wetting cycles," Journal of Geotechnical and Geoenvironmental Engineering, vol. 140, no. 2, Article ID 06013001, 2014.

[15] L. Chen, X. L. Zhao, L. Lu, Y. Zhang, W. Z. Gao, and B. B. Xia, "Shearstrengthtestofexpansivesoilswithdifferent cracks development characteristics," in 3rdInternational Symposium onGeomechanics fromMicro toMacro ,Cambridge ,England, K. Soga, K. Kumar, G. Biscontin, and M. Kuo, Eds., vol. Volume 2, pp. 1267-1272, CRC Press, BocaRaton ,USA, 2015.

[16] Z. Han and S. K. Vanapalli, "Stiffness and shear strength of unsaturated soils in relation to soil-water characteristic curve," Géotechnique, vol. 66, no. 8, pp. 627-647, 2016.

[17] J. Xiao, H. P. Yang, J. H. Zhang, and X. Y. Tang, "Properties of drained shear strength of expansive soil considering low stresses and its influencing factors," International Journal of Civil Engineering, vol. 16, no. 10B, pp. 1389-1398, 2018.

[18] F. H. Lee, K. W. Lo, and S. L. Lee, "Tension crack development in soils," Journal of Geotechnical Engineering, vol. 114, no. 8, pp. 915-929, 1988.

[19] V. Y. Chertkov, "Using surface crack spacing to predict crack network geometry in swelling soils," Soil Science Society of America Journal, vol. 63, pp. 1918-1921, 1999.

[20] F. Yazdandoust and S. S. Yasrobi, "Effect of cyclic wetting and drying on swelling behavior of polymer-stabilized expansive clays," Applied Clay Science, vol. 50, no. 4, pp. 461-468, 2010.

[21] C.-S. Tang, Y.-J. Cui, B. Shi, A.-M. Tang, and C. Liu, "Desiccation and cracking behaviour of clay layer from slurry state under wetting-drying cycles," Geoderma, vol. 166, no. 1, pp. 111-118, 2011.

[22] R. A. Stirling, S. Glendinning, and C. T. Davie, "Modelling the deterioration of the near surface caused by drying induced cracking," Applied Clay Science, vol. 146, pp. 176-185, 2017.

[23] J. J. Zhang, B. W. Gong, B. Hu, X. W. Zhou, and J. Wang, "Study of evolution law of fissures of expansive clay under wetting and drying cycles," Rock Soil Mech, vol. 32, pp. 2729-2734, 2011.

[24] K. K. Watson, R. J. Reginato, and R. D. Jackson, "Soil water hysteresis in a field soil," Soil Science Society of America Journal, vol. 39, no. 2, pp. 242-246, 1975.

[25] J. Graham, "Embankment stability on anisotropic soft clays," Canadian Geotechnical Journal, vol. 16, no. 2, pp. 295-308, 1979.

[26] H. Peron, J. Y. Delenne, L. Laloui, and M. S. El Youssoufi, "Discrete element modelling of drying shrinkage and cracking of soils," Computers and Geotechnics, vol. 36, no. 1-2, pp. 61-69, 2009.

[27] D. Rosenbalm and C. E. Zapata, "Effect of wetting and drying cycles on the behavior of compacted expansive soils," J.Mater.Civil Eng, vol. 29, 2016. 